\title{
A generic model of thinning and stand density effects on forest growth, mortality and net increment
}

\author{
Oskar FRANKLIN ${ }^{1 *}$, Kentaro AOKI $^{1}$, Rupert SEIDL ${ }^{2}$ \\ ${ }^{1}$ IIASA International Institute for Applied Systems Analysis, 2361 Laxenburg, Austria \\ ${ }^{2}$ Institute of Silviculture, Department of Forest- and Soil Sciences, University of Natural Resources and Applied Life Sciences (BOKU) Vienna, \\ Peter Jordan Straße 82, 1190 Wien, Austria
}

(Received 30 October 2008; revised version 24 February 2009; accepted 24 March 2009)

Keywords:

dead wood /

optimal density /

forest model /

closure /

forestry

\author{
Mots-clés : \\ bois mort / \\ densité optimale / \\ modèles de forêts / \\ fermeture / \\ foresterie
}

\begin{abstract}
- For assessing forest thinning effects at large (i.e. continental) scale, data scarcity and technical limitations prevent the application of localized or individual-based thinning models.

- Here we present a simple general framework to analyze and predict the effects of thinning on growth and mortality, including the following stand density development. The effects are modeled in relative terms so that the model can be parameterized based on any thinning experiment that includes an unthinned control, regardless of site conditions and stand age.

- The model was tested against observed thinning effects on growth and mortality from five temperate and boreal species (all species pooled $r^{2}=0.51$ ). It predicted a maximum increase in net stem biomass increment of $16 \%$ and a reduction in density-related mortality of $75 \%$ compared to unthinned conditions at stand densities of around $70 \%$ of the maximum (increment optimal density).

- A sensitivity analysis revealed overlapping ranges of near optimal density (net increment within 95\% of optimal) among all tested species, suggesting that one thinning scenario can be used for many species. The simple and general formulation of thinning effects based on only five parameters allows easy integration with a wide range of generic forest growth models.
\end{abstract}

Résumé - Un modèle générique des effets de l'éclaircie et de la densité des peuplements sur la croissance des forêts, la mortalité et l'accroissement net.

- Pour évaluer les effets de l'éclaircie en forêt à une large échelle (c'est-à-dire continentale), la rareté des données et des limitations techniques empêchent l'application de modèles d'éclaircie localisés ou individuels.

- Ici, nous présentons un simple cadre général pour analyser et prédire les effets de l'éclaircie sur la croissance et la mortalité, y compris le développement suivant de la densité du peuplement. Les effets sont modélisés en termes relatifs, de sorte que le modèle peut être paramétré sur la base de n'importe quelle expérience d'éclaircie qui inclut un témoin non éclairci, indépendamment des conditions du site et de l'âge du peuplement.

- Le modèle a été testé contre les effets de l'éclaircie observés sur la croissance et la mortalité de cinq espèces tempérées et boréales $\left(r^{2}=0,51\right)$ pour toutes les espèces mises en pool). Il a prédit une augmentation maximale de l'accroissement net de la biomasse des troncs de $16 \%$ et une réduction de la mortalité liée à la densité de $75 \%$ par rapport aux conditions de non éclaircie de densité de peuplement de l'ordre de $70 \%$ du maximum (densité de l'accroissement optimal).

- Une analyse de sensibilité a révélé des écarts de chevauchements près de la densité optimale (accroissement net dans $95 \%$ de l'optimal) entre toutes les espèces testées, suggérant que un scénario d'éclaircie peut être utilisé pour de nombreuses espèces. La simple et générale formulation des effets de l'éclaircie basée sur seulement cinq paramètres permet une intégration facile avec une large gamme de modèles génériques de croissance des forêts.

\footnotetext{
* Corresponding author: franklin@iiasa.ac.at
} 


\section{INTRODUCTION}

Thinning is an important means to pursue silvicultural objectives (e.g. selection of desired tree species, promotion of stability and stem quality) that generates income opportunities during the long rotation periods in temperate and boreal forest ecosystems. As a centrepiece in stand level forest management, thinning has received considerable attention in forest research. A number of empirical studies and thinning trials were initiated to quantify the effect of different thinning intensities, intervals and structures (i.e., thinning from above, thinning from below) mainly on stemwood growth (e.g. Assmann, 1961; Pretzsch, 2005). Besides a focus on an improved physiological understanding of thinning effects, various approaches of representing such effects in the framework of forest models have been presented (Söderbergh and Ledermann, 2003), ranging from empirical approaches to physiology-based models.

The former are strongly linked to the advent of empirical, individual tree growth models in the second half of the 20th century. Such concepts, starting with Newnham (1964), relate individual tree growth to a tree's environment (i.e. competition) and are thus able to simulate the liberating effect of thinning on the remaining individuals. A number of competition indices have been developed for this purpose, resulting in distance-dependent and distance-independent tree growth models (e.g. Hynynen et al., 2005; Monserud and Sterba, 1999; Siitonen et al., 1999; Sterba and Monserud, 1997). For parameterization of these empirical models for local to national applications, data sets ranging from research trials to national forest inventories have been used (Hasenauer, 2006). Such empirical models are widely used in forest management planning at the operational scale today (e.g. Crookston and Dixon, 2005).

In contrast, physiology-based approaches have been mainly used to investigate how the processes affecting growth and allocation change as a result of thinning. For example, Zeide (2001) presented a process-oriented framework to thinning effects related to closure and environmental variables. Recently, Petritsch et al. (2007) introduced prescribed time-lags in a biogeochemical process model to achieve a better representation of growth and allocation regimes after thinning. Although offering a generalized framework, process-based models are still limited with regard to management support mostly due to their data and parameterization requirements. Moreover, process based models often suffer from a lack of precision in longer term predictions for scenario analyses, due to compounding of errors (Mason and Dzierzon, 2006). In contrast, empirical models have been found to achieve high precision within their domain of development and parameterization, yet are of limited generality.

In large scale scenario models for policy support the challenge is thus to provide a thinning framework that is (i) general enough to be applicable at continental scale and (ii) confined in complexity to correspond to the limited structural information available in models operating at that scale and in order to facilitate parameterization. Consequently, although thinning is a powerful intervention towards various strategic management goals in forestry, large scale modeling approaches have been strongly limited in addressing thinning effects. Large scale carbon budgeting tools have, for instance, widely neglected the effects of thinnings (e.g. Kurz and Apps, 1999). In EFISCEN, the most widely applied continental scale scenario model in Europe, the representation of thinning is limited by the model structure of age-volume matrices (Schelhaas et al., 2007). For example, the thinning effect on growth is essentially independent of development stage in EFISCEN and changed mortality patterns as an effect of thinning are simplified to a complete cancellation of mortality in thinned stands. The problem that the modelled thinning effect is not realistically dependent on the development stage applies also to the approach taken by Böttcher et al. (2008) although in their model, mortality in response to thinning is reduced in a more realistic gradual fashion. More realistic stand and individual-based thinning models relying on empirical findings of growth and yield studies, such as the MELA system (Siitonen et al., 1999), Motti (Hynynen et al., 2005), and Prognaus (Sterba and Monserud, 1997), have to date not been applied and validated at continental scale to our knowledge.

Considering the limitations in the current state of the art continental scale scenario models, our overall objective was to develop a general and simple thinning framework applicable at large scales, based on a quantitative density - growth - mortality relationship. Notwithstanding the findings on the importance of the local context of thinning effects, our aim is to simplify and generalize available knowledge for use in policy support frameworks. The purpose is to derive a model framework predicting stand responses to thinning, or a sequence of thinnings, in terms of density, growth and mortality. We develop models for thinning effects on growth and mortality separately which are then combined to predict the total effect in terms of net stand growth and mortality. The effects are modelled as functions of density relative to maximum stand density (closure). Omitting absolute density numbers, the model can be generalized to any forest stand conditions regardless of absolute density and biomass values. With respect to stem biomass productivity, this framework should also allow an assessment of potential "optimal" closure and associated thinning scenarios and their consequences for mortality (dead wood production). The underlying principles, based on stand level forest functioning, are evaluated for five borealtemperate tree species.

\section{MATERIALS AND METHODS}

\subsection{Theory and models}

The model is based on the relationship between the self-thinning limit, i.e. the maximal number of trees that can coexist on a fixed area $\left(N_{\max }\right.$; cf. symbols in Tab. I) and the mean tree size $(b)$. The effects of thinning, an imposed reduction in density, are modeled based on how much the resulting density deviates from the maximum density (self-thinning limit) and how this affects growth and mortality dynamically as the stand re-closes. As we are using relative measures of growth, mortality and density, the model can be applied to both biomass and volume data. The general results and conclusions are 
Table I. Symbols.

\begin{tabular}{|c|c|c|}
\hline Symbol & Unit & Description \\
\hline$B$ & $\mathrm{Mg} \mathrm{ha}^{-1}$ & Stand stem biomass \\
\hline$b$ & $\mathrm{Mg}$ & Mean stem biomass of a single tree \\
\hline$d B_{d} / d t_{c}$ & $\mathrm{Mg} \mathrm{ha}^{-1} \mathrm{y}^{-1}$ & Production of dead stem biomass \\
\hline$d B / d t_{c}$ & $\mathrm{Mg} \mathrm{ha}^{-1} \mathrm{y}^{-1}$ & Increment of standing stem biomass \\
\hline$N$ & $\mathrm{ha}^{-1}$ & Number of trees \\
\hline$N_{\max }$ & $\mathrm{ha}^{-1}$ & Maximum number of trees at a fixed $b$ \\
\hline$k$ & $\mathrm{Mg}$ & $\begin{array}{l}b \text { where } N_{\max }=1 \text { (position of the self } \\
\text { thinning line, Eq. (1)) }\end{array}$ \\
\hline$\alpha$ & - & Slope of the self thinning Equation (1) \\
\hline$m$ & $\mathrm{y}^{-1}$ & $\begin{array}{l}\text { Density independent mortality, } \\
\text { fraction of total biomass }\end{array}$ \\
\hline$q$ & - & $\begin{array}{l}\text { Size }(b) \text { of the trees that dies during self } \\
\text { thinning relative to the mean tree } b\end{array}$ \\
\hline$c$ & - & Closure $=N / N_{\max }$ \\
\hline$c_{t}$ & - & maximum closure allowed in a thinned stand \\
\hline$u_{g}$ & - & Gross growth rate relative to a closed stand \\
\hline$\gamma_{g}$ & - & Parameter of $u_{g}$ \\
\hline$u_{m}$ & - & Mortality relative to a closed stand \\
\hline$\gamma_{m}$ & - & Parameter of $u_{m}$ \\
\hline$f_{t}$ & - & Fraction biomass removed in a thinning \\
\hline
\end{tabular}

not dependent on the combination of the thinning framework with a particular growth model. However, for some numerical illustrations, a growth model (Franklin et al., 2009) is used in this paper. The model is evaluated for even-aged stands.

\subsection{Stand density and self thinning}

To model the number of trees and the effects of the changes in forest stand density during the development of a stand, a self-thinning equation is used. For stands growing at maximum density (closed stands)

$$
b=k N_{\max }^{\alpha}
$$

where $N_{\max }$ is number of trees and $b$ is the biomass of the average tree. For a fixed area, the number of trees $(N)$ is decreasing as $b$ and the total stand biomass $(B)$ are increasing. Although individual stands do generally not grow continuously along this line due to discontinuous mortality events, for our purposes, a self-thinning line (Eq. (1)) is a sufficient approximation of stand development of a closed stand. Although the existence of a universal $\alpha$ (slope of the self-thinning line) has been suggested based on empirical evidence (Reineke, 1933), theory for local competition and probability theory (Dewar and Porte, 2008), empirical studies have shown substantial variability in $\alpha$, e.g. among species (Weller, 1987). In our analysis we allow $\alpha$ to vary among species.

Net $B$ increment of a closed stand can be expressed as

$$
\frac{\mathrm{d} B}{\mathrm{~d} t}=\frac{\mathrm{d}(b N)}{\mathrm{d} t}=q b \frac{\mathrm{d} N}{\mathrm{~d} t}+N \frac{\mathrm{d} b}{\mathrm{~d} t},
$$

where the first and second terms represent self-thinning mortality and gross increment, respectively. To represent the relative size difference between trees that die in self-thinning and the mean tree, $b$ in the selfthinning term in Equation (2) is multiplied by a factor $q=$ biomass of a dying tree/mean tree biomass. By inserting equation (1) in the expression above, it can be shown that mortality in a closed stand

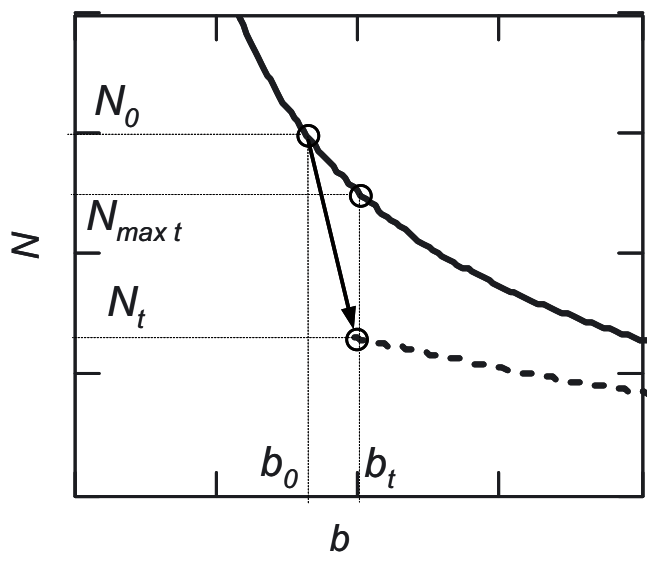

Figure 1. Closure (c) after a thinning. The figure shows thinning removal of $N_{0}-N_{t}$ trees, which are smaller than the average tree (thinning from below). This leads to an increase in mean tree size $(b)$ from $b_{0}$ before thinning to $b_{t}$ after the thinning. $c$ after the thinning is given by $N$ after thinning $\left(N_{t}\right)$ divided by the $N_{\max }$ (solid line) corresponding to $b_{t}\left(N_{\max t}\right)$. The dashed line shows the development after thinning.

$\left(\mathrm{d} B_{d} / \mathrm{d} t_{c}\right.$; Eq. (3)) is proportional to the increment of live biomass $\left(\mathrm{d} B / \mathrm{d} t_{c}\right)$

$$
\frac{\mathrm{d} B_{d}}{\mathrm{~d} t_{c}}=\frac{\mathrm{d} B}{\mathrm{~d} t_{c}} \frac{q}{\alpha+1} .
$$

It is natural that $q$ is less than 1 , since smaller trees are suppressed by larger, e.g. in terms of light absorption, and therefore are more likely to die in the self-thinning process. In reality $q$ may change with age as the stand develops from a left skewed size distribution towards a normal distribution for old stands (Coomes and Allen, 2007). However, for simplicity and as we mainly focus on managed forests within a relatively narrow age-span (i.e., managed ecosystems and not old growth forests), we assume that $q$ is constant over the time periods of our thinning response observations.

\subsection{Thinning effects}

Thinning causes reduction of density and associated reduction in resource use and competition, which increase the growth of the remaining trees and reduces their mortality rate. On the stand scale this effect can be divided into two effects. First, the total stand production (NPP) is reduced (although very slightly for light thinning) because of the reduced resource capture (Zeide, 2004). Second, the self-thinning (density dependent) mortality is reduced, which is linked to the improved growth of the remaining trees.

To model these effects in a way that is independent of site productivity we use the concept relative density or closure ( $c$; Garcia, 1990 ), i.e. the number of trees relative to the maximum number of trees $\left(N_{\max }\right.$, given by the self-thinning limit) for a fixed individual tree size $(b)$.

If the mean size of trees removed are the same as that of the remaining trees, $c$ after thinning from a closed stand $(c=1)$ is simply equal to removed volume/total volume or removed number of trees/total number of trees. As described in Figure 1, if the removed trees are of a different mean size than the remaining trees, $c$ after thinning $\left(c_{t}\right)$ is calculated based on the new $b$ and $N$ after 

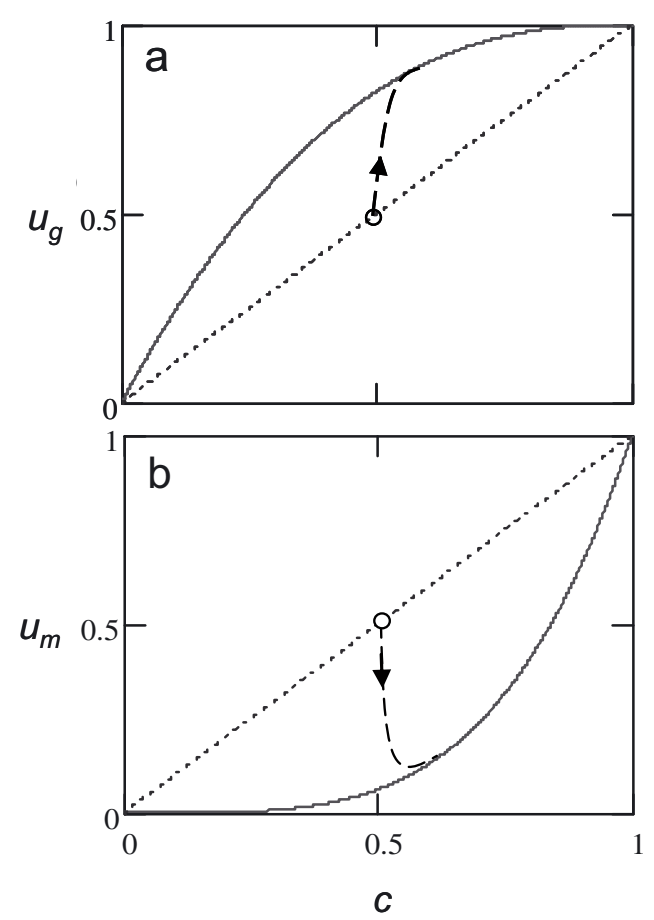

Figure 2. The response of growth rate $\left(u_{g}\right)$ and mortality $\left(u_{m}\right)$ to stand closure $(c)$. Dotted straight lines show the responses immediately after thinning before the trees have utilized the new growing space available. The solid lines show the acclimated responses and the dashed lines show the effect of a thinning to $c=0.5$ followed by acclimation.

the thinning, $b_{t}$ and $N_{t}$, respectively, using equation (1), which yields $c_{t}=\frac{N_{t}}{N_{\max t}}=\frac{N_{t}}{\left(b_{t} / k\right)^{1 / \alpha}}$.

After thinning there is a reduction in stand growth rate through reduced resource absorption, where stem-wood growth relative to that of a closed stand is related to closure (c) according to $u_{g}$ (Eq. (4)). However, the growth reduction is not proportional to the reduction in $c$ because, although they are fewer, each of the remaining trees receives more light and other resources. For example, if only a small fraction of the trees are removed in a dense canopy with some depth, the total light absorption declines very little due to the overlapping of tree crowns in the path of incident light (for non zenith angles). However, if the density is very low (no overlapping of tree crowns in the path of light) a reduction in density will lead to a proportional reduction in light absorption. Thus, the slope of the change in relative stand radiation absorption in response to reduced $c\left(\mathrm{~d} u_{g} / \mathrm{d} c\right)$ declines with density as $\mathrm{d} u_{g} / \mathrm{d} c \rightarrow 0$ when $c \rightarrow 1$, and $\mathrm{d} u_{g} / \mathrm{d} c>1$ when $c \rightarrow 0$, which is a pattern described by equation (4). We expect similar relationships in case resources other than light are more limiting, such as water and nutrients, although this is less clear (see discussion).

$$
u_{g}=1-(1-c)^{\gamma_{g}}
$$

$\gamma_{g}$ is determined from experimental data collected from the literature (see below).

Some studies have shown that the growth of individual trees does not increase immediately after a thinning and that the trees must physiologically acclimate before they can fully utilize the increased growing space (e.g. Pukkala et al., 2002). This acclimation can for example be related to redistribution of nitrogen and adjustment of photosynthetic capacity (Medhurst and Beadle, 2005). However, a time-lag in growth response after thinning is not always observed (Norgrove and Hauser, 2002) and its duration may be small compared to the total duration of the thinning effect on stand growth (Pukkala et al., 2002). Thus, for simplicity we neglect this effect and exclude from our analysis growth measurements representing very short periods directly after thinning where there was evidence that the thinning effect on growth of individual trees $\left(\left(\mathrm{d} B / \mathrm{d} t+\mathrm{d} B / \mathrm{d} t_{d}\right) / c\right)$ has not yet peaked.

In addition to the growth rate, the self-thinning rate is affected by closure $(c)$. The density dependent self-thinning mortality (ddmortality) is strongly negatively correlated with growth rate within a stand (Wyckoff and Clark, 2002) implying that increased growth rate of individual trees diminishes dd-mortality. If there is a minimum growth rate required to survive (cf. Keane et al., 2001), mortality could theoretically be completely cancelled after a thinning since the growth rate of all trees will be raised above this minimum growth limit. However, due to temporal variability in growth rates there will be some risk of mortality even if the mean value of growth rate is above the limit for survival. Depending on growth rate variability there will therefore be a more or less strong reduction in dd-mortality rate in response to thinning. Striving for simplicity we assume that Equation (5) captures the overall response of dd-mortality to $c$.

$$
u_{m}=c^{\gamma_{m}} .
$$

A similar equation for adding density dependent self-thinning to a growth model has successfully been used to predict forest growth in agreement with yield tables (Tang et al., 1994).

Mortality other than dd-mortality is included in the growth model as density independent mortality (di-mortality), see below.

\subsection{Data preparation and parameterization of thinning effects}

Data was collected from studies that included both thinned and un-thinned control stands, and where the dominant form of mortality was dd-mortality, as opposed to random, disturbance or age related mortality. Datasets and data points (Tab. II, Tab. A available at www. afs-journal.org) from plots or years that had been subject to significant mortality other than dd-mortality, such as insect attack and storm damage, were excluded. In addition to that indicated in the original publications, stands subject to non dd-mortality were identified by an increase in mortality per tree after thinning (dd-mortality per tree decreases after thinning).

To determine $c$ of the thinned stands, we used a self-thinning equation (Eq. (1)) parameterized for the corresponding control stands to calculate the maximum number of trees $\left(N_{\max }\right)$ at the given individual tree size $(b)$ of the thinned stands. $N$ of the thinned stands was then divided by $N_{\max }$ to obtain $c$ of the thinned stand. This means that the control and thinned stands are compared at the same $b$. By division with the values for control plots over the same observation period, relative thinning effects on gross growth and mortality were calculated as functions of $c$ and then used to fit the parameters of Equations (4) and (5). In using this method it is implicitly assumed that growth and mortality rate do not change significantly during the period of observation, which is true for the approximately linearly growing stands used in this study or if the observation period is short.

The relative size of self-thinned trees to the mean tree size $(q$, Eq. (3)) was estimated for all control plot observations. 
Table II. Thinning experiments - control plot data.

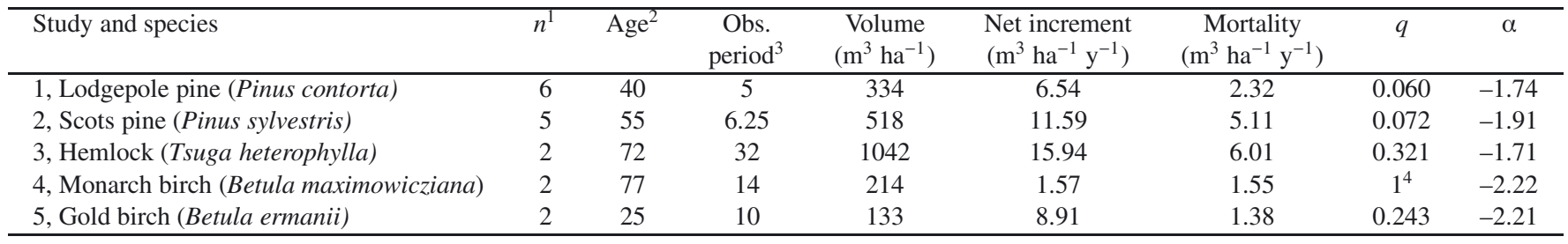

All values are means for each species. ${ }^{1}$ Number of observations, ${ }^{2}$ mean stand age during experiment, ${ }^{3}$ duration over which mean responses were estimated, ${ }^{4}$ adjusted value, measured value was 1.27. References for studies 1-5, respectively: Johnstone (2002), Montero et al. (2001), Omule (1988), Watanabe (2002), Asai (1997). The complete data set is shown in Appendix Table.
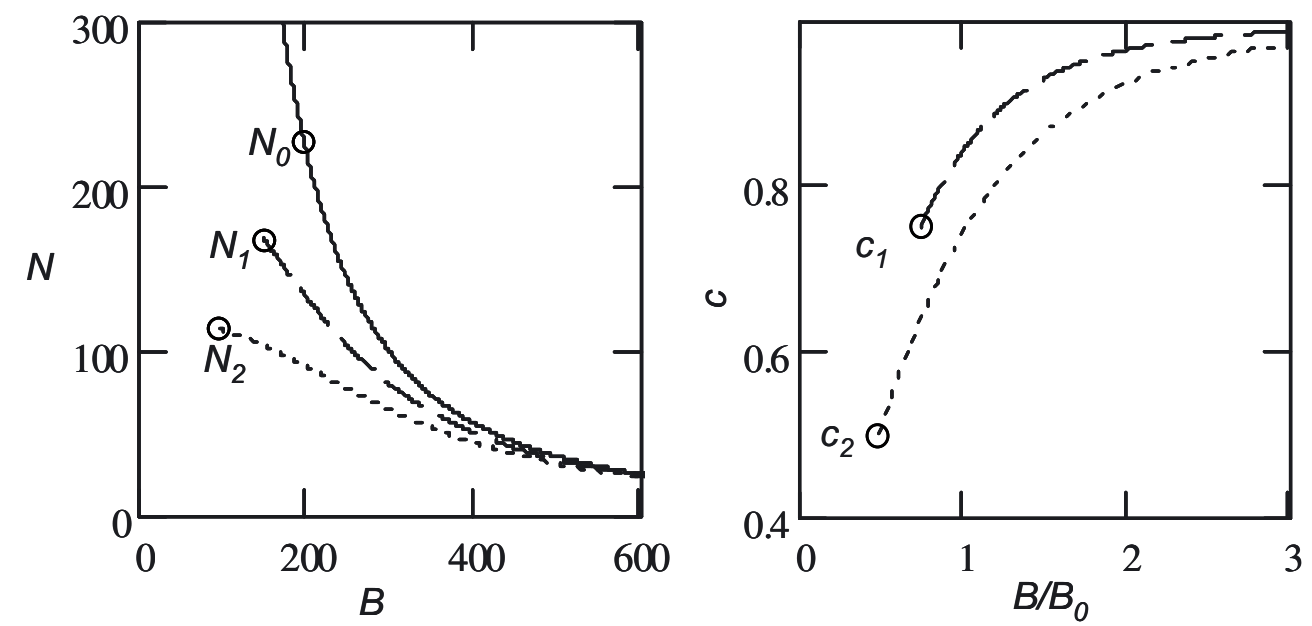

Figure 3. Development of tree numbers $(N)$ and closure $(c)$ after thinning of a closed stand $\left(B=B_{0}, N=N_{0}, c=1\right)$ at two levels of biomass removal, $25 \%\left(N_{1}, c_{1}\right.$ dashed lines $)$ and $50 \%\left(N_{2}, c_{2}\right.$ dotted lines). Parameter values: $k=3000, \gamma_{m}=4, \alpha=-1.5$.

\subsection{Growth and mortality dynamics of thinned stands}

For net increment $(\mathrm{d} B / \mathrm{d} t)$ the total effect of a thinning depends on the relative strength of the effects on stand growth and mortality. For a moderate thinning, the avoided self-thinning usually more than compensates for the reduction in total stand production so that net stem increment is enhanced. After a thinning, the $c$ of the thinned stand increases with time and may eventually approach a fully closed stand ( $c=1$; Fig. 3).

In a closed stand, net increment $\left(\mathrm{d} B / \mathrm{d} t_{c}\right)$ and mortality $\left(\mathrm{d} B_{d} / \mathrm{d} t_{c}\right)$ are linked according to equation (3). In a thinned (open) stand, total stem wood production is reduced according to equation (4) and self thinning (second term in Eq. (6)) is reduced according to equation (5) as functions of closure $(c)$

$$
\frac{\mathrm{d} B}{\mathrm{~d} t}=\left(\frac{\mathrm{d} B}{\mathrm{~d} t_{c}}+\frac{\mathrm{d} B_{d}}{\mathrm{~d} t_{c}}\right) u_{g}-\frac{\mathrm{d} B_{d}}{\mathrm{~d} t_{c}} u_{m}
$$

As this study focuses on the analysis of managed stands where density independent mortality is low, density independent mortality is ignored in equation (6). However for other applications and for our illustrated scenario below, density independent mortality is added to the framework. By definition density independent mortality $\left(\mathrm{d} B_{d i} / \mathrm{d} t\right.$, Eq. (7)) does not change as a function of $c$. For spruce stands mortality has been shown to be higher for very small and very big trees (Monserud and Sterba, 1999), i.e. slow growing stages (in terms of absolute growth rate) of stand development, and is therefore modeled to be a function of the net increment $(\mathrm{d} B / \mathrm{d} t)$ relative to its maximum over the stand development $\left(\mathrm{d} B / \mathrm{d} t_{\max }\right)$

$$
\frac{\mathrm{d} B}{\mathrm{~d} t_{d i}}=m B\left(1-\frac{\mathrm{d} B / \mathrm{d} t}{\mathrm{~d} B / \mathrm{d} t_{\max }}\right) .
$$

Because of its independence of $c$, density independent mortality in this study only plays a role in the illustration of thinning scenarios below, where $m$ was assumed to be $1 \%$ per year.

Using equations (1)-(6), the stand behavior in terms of biomass $(B)$ and mortality $\left(B_{d}\right)$ can be derived as functions of closure $(c)$ and time for thinned stands.

The relationship between $c, N$ and $B$ can also be described independently of time and $\mathrm{d} B / \mathrm{d} t$ using equations (1), (3), (5) and (6). To illustrate their behavior, we derive analytical expressions for the development of $c$ and $N$ after a thinning removal of a fraction $f_{t}$ of the standing biomass just before thinning $\left(B_{0}\right)$, as functions of $B$ development after the thinning:

$$
\begin{aligned}
c & =\left[1-\left(\frac{B}{B_{0}} \frac{1}{1-f_{t}}\right)^{\frac{\gamma_{m}}{\alpha}}\left(1-\left(c_{0}\left(1-f_{t}\right)\right)^{-\gamma_{m}}\right)\right]^{-1 / \gamma_{m}} \\
N & =\left[(k / B)^{\gamma_{m} / \alpha}+\left(\frac{k\left(1-f_{t}\right)^{-(a+1)}}{B_{0} c_{0}}\right)^{\gamma_{m} / \alpha}-\left(\frac{k}{B_{0}\left(1-f_{t}\right)}\right)^{\gamma_{m} / \alpha}\right]^{-\alpha /\left(\gamma_{m}(\alpha+1)\right)}
\end{aligned}
$$


In case the mean size of the trees removed in a thinning is not equal to the mean tree size of the stand, $B_{0}$ in Equations (8) and (9) must be recalculated to match $b$ after thinning $\left(b_{t}\right.$, Fig. 1).

The behavior of $N$ and $c$ after a thinning (Eqs. (8) and (9)) is illustrated in Figure 3. The development of $c$ and $N$ after a thinning of a closed stand depend on the fraction biomass removed in the thinning $\left(f_{t}\right)$, the maximum $N$ as a function of $B$ (the self thinning equation, Eq. (1)) and the density response of self thinning mortality $\left(\gamma_{m}\right.$, Eq. (5)).

Because the Equations (4)-(9) above are independent of the functional form of the basic increment function $\left(\mathrm{d} B / \mathrm{d} t_{c}\right)$, the framework can be used to describe the thinning response in combination with any basic growth function. In summary, the parameters that are needed to add a thinning response to any growth model of standing biomass $(B)$ are the parameters of the self thinning equation $k$, and $\alpha$, the growth and mortality response parameters $\gamma_{g}$ and $\gamma_{m}$, and the closure before thinning, $c_{0}$. To obtain a time dependent response (as opposed to only $B$ dependent) it is also necessary to know the relative size of selfthinning compared to surviving trees $(q)$, see below.

\subsection{Optimal closure and thinning}

To determine the optimal $c$ in terms of net stem biomass increment we consider net increment $\mathrm{d} B / \mathrm{d} t$ (Eq. (6)) as $c$ is reduced. Net increment is decreased due to reduced gross growth at the same time as it is increased due to reduced self thinning mortality (Fig. 2). The maximum net increment is obtained where the sum of the two effects on $\mathrm{d} B / \mathrm{d} t$ (Eq. (6)) is maximized. Using Equation (3), Equation (6) can be reformulated as

$$
\begin{aligned}
\frac{\mathrm{d} B}{\mathrm{~d} t}=\left(\frac{\mathrm{d} B}{\mathrm{~d} t_{c}}+\frac{\mathrm{d} B}{\mathrm{~d} t_{c}} \frac{q}{\alpha+1}\right) u_{g}- & \frac{\mathrm{d} B}{\mathrm{~d} t_{c}} \frac{q}{\alpha+1} u_{m}= \\
& \frac{\mathrm{d} B}{\mathrm{~d} t_{c}}\left(\left(\frac{q}{\alpha+1}+1\right) u_{g}-\frac{q}{\alpha+1} u_{m}\right)
\end{aligned}
$$

$\mathrm{d} B / \mathrm{d} t$ is maximized by setting Equation $(10)=0$, inserting the functions for $u_{m}$ and $u_{g}$ (Eqs. (4) and (5)) and solving for $c$,

$$
\begin{aligned}
\frac{\mathrm{d}}{\mathrm{d} c}\left(\left(\frac{q}{\alpha+1}+1\right) u_{g}-\frac{q}{\alpha+1} u_{m}\right)=\gamma_{g}(1+ & \left.\frac{q}{\alpha+1}\right)(1-c)^{\gamma_{g}-1} \\
& -\gamma_{m} \frac{q}{\alpha+1} c^{\gamma_{m}-1}=0 .
\end{aligned}
$$

To obtain the optimal $c$, Equation (11) must be solved numerically.

A sensitivity analysis of optimal $c$ was conducted with regard to the density effects on mortality $\left(\gamma_{m}\right)$ and growth $\left(\gamma_{g}\right)$ and relative size of self-thinned trees $(q)$. Net increment gain in a thinned stand was analyzed in comparison to un-thinned $(c=1)$ stands.

The equations above illustrate the responses of a forest stand to a specified thinning. To describe the development of a forest stand managed by successive thinnings and calculate an optimal thinning level in terms of maximized biomass increment, it is also necessary to describe how and when thinnings are initiated.

In order to illustrate an example of an optimal thinning scenario based on our model and the optimal $c$, a thinning scenario was designed to keep $c$ within a near-optimal range. We base our thinning scenario on the assumption that the purpose of the thinning is to enhance biomass productivity. In addition, although we do not explicitly consider any economical factors, the thinning scenario should not be unrealistic in relation to practical applications that include management costs and benefits. The number of thinnings should not be too
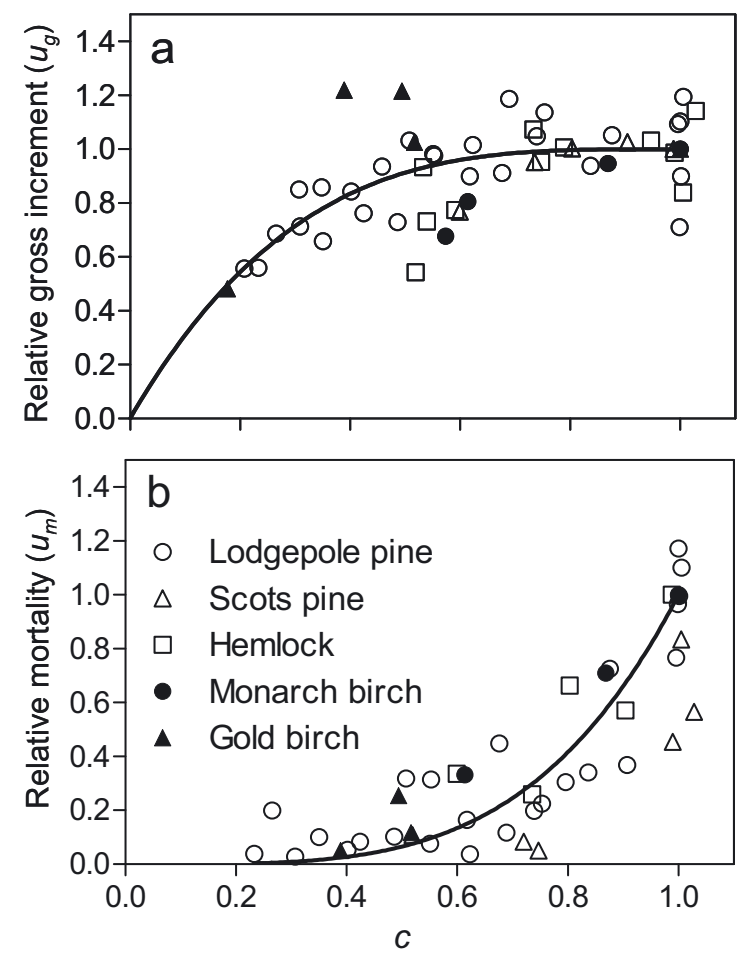

Figure 4. Relative gross stem-wood increment (a) and mortality (b) as functions of closure $(c)$. Solid lined are best fits for all species pooled (see Tab. II). One point for Scots pine was outside of the plotted range (relative mortality $=2.14, c=0.95$ ).

high, since very frequent thinnings would be cost-intensive. Furthermore we presume that no thinning occurs before the stand has reached a certain biomass and tree size because very early thinnings would yield relatively little harvest of thin stems (low value) at the same time as costs are high due to the large number of stems that need to be cut. The point of first thinning also depends on the planting density (for planted stands) as the stand must have a sufficiently high closure (c) before thinning is beneficial (see below). We set the timing of the first thinning equal to the point of peak growth, which in forest stand simulations with realistic planting densities (much lower than maximum density $\left(N_{\max }\right)$, i.e. $\left.c \ll 1\right)$ nearly coincided with $c$ reaching the computed limit for optimal thinning $(c \approx 0.85)$.

\section{RESULTS}

\subsection{Density effects on growth and mortality}

Table III and Figure 4 show the fitted parameters and the data for relative growth and mortality as functions of $c$ for different species and for all species pooled. There are statistically significant differences in $\gamma_{g}(p=0.0004)$ and $\gamma_{m}(p=0.044)$ among species although the number of data points is small and confidence intervals are large for most species. Residual analysis showed that the $c$ effect on gross increment is reasonably well described by equation (4) with a $r^{2}=0.41$ for all species pooled, and with higher $r^{2}$ for the species specific fits (Tab. III). For mortality, the agreement between model and 
Table III. Thinning effects on gross increment and mortality .

\begin{tabular}{|c|c|c|c|c|c|c|c|c|}
\hline Species & \multicolumn{4}{|c|}{ Effect on gross increment $\left(u_{g}\right)$} & \multicolumn{4}{|c|}{ Effect on density dependent mortality $\left(u_{m}\right)$} \\
\hline Scots pine & 7 & 1.915 & 1.080 to 2.750 & 0.4975 & 3 & 8.63 & -2.534 to 19.79 & -6.403 \\
\hline Monarch birch & 4 & 1.495 & 1.158 to 1.833 & 0.89 & 3 & 2.313 & 2.063 to 2.563 & 0.997 \\
\hline Gold birch & 5 & 5.699 & -2.168 to 13.57 & 0.53 & 4 & 2.589 & 1.402 to 3.776 & 0.35 \\
\hline All species & 43 & 3.518 & 2.775 to 4.260 & 0.41 & 35 & 3.933 & 3.148 to 4.718 & 0.60 \\
\hline
\end{tabular}

$r^{2}$ values are based on the agreement between measured and modeled effects, $u_{g}$ and $u_{m}$, based on their estimated corresponding parameters, $\gamma_{m}$ and $\gamma_{m}$, respectively.

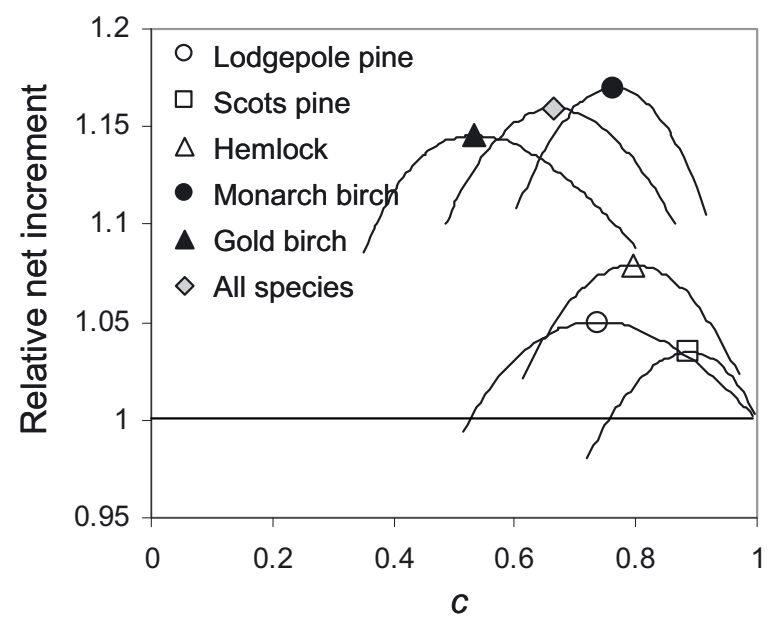

Figure 5. Closure $(c)$ that maximizes net increment (gross stem growth - mortality) and relative net increment (RNI, net increment - net increment of closed stands, at the same mean tree biomass) for different species. Lines show the range where RNI $>95 \%$ of optimum. Parameter values in Tables I-III.

data is better, $r^{2}=0.60$ for all species pooled, but lower for the pine species (Tab. III). A residual analysis revealed a tendency for overestimation of mortality at high $c$ and underestimation at low $c$ for the pine species.

\subsection{Optimal closure}

Optimization of current net increment (Eq. (6)) with respect to $c$ resulted in optimal $c$ between 0.53 and 0.88 and increases in relative net increment compared to un-thinned conditions (RNI) between 3.5\% and 17\% (Fig. 5). However, the ranges of $c$ where RNI is within $95 \%$ of optimal overlap for all species for $c$ between 0.71 and 0.81 . For all species pooled, the optimal $c$ was 0.68 which led to RNI $=16 \%$ and a $75 \%$ reduction in mortality (dead wood production) compared to un-thinned conditions. The value of RNI was more variable among species than the optimal $c$ and the $95 \%$ of optimum intervals did not overlap except within the groups broad leafed species (gold birch and monarch birch) and needle leafed species (lodgepole pine, Scots pine and hemlock), which had a lower RNI than the birches.

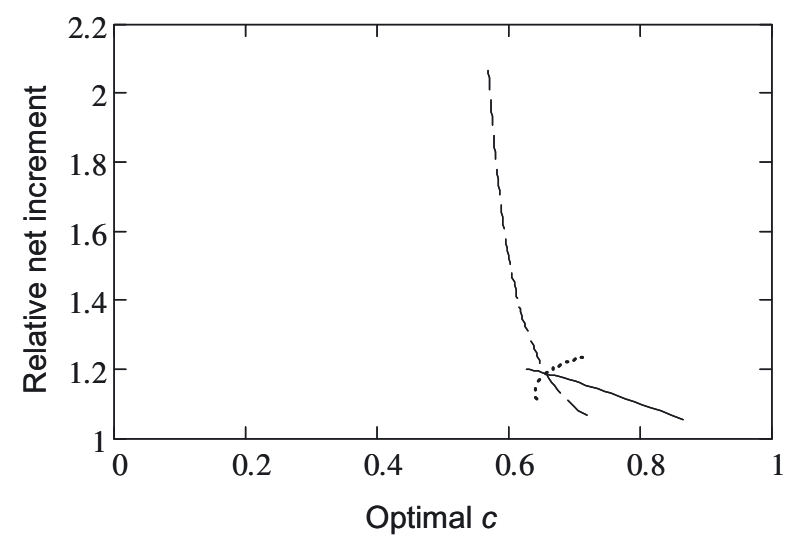

Figure 6. Sensitivity of optimal closure $(c)$ and optimal relative net increment (RNI, net increment - net increment of closed stands, at the same mean tree biomass) for intervals, starting to the left in the figure, for $q$ ( $=1$ to 0.08 , dashed line), $\gamma_{g}(=4$ to 1.5 , solid line) and $\gamma_{m}(=1.8$ to 8.6 dotted line). The parameter intervals correspond to the range of estimated values (Tab. II). Baseline parameter values: $q=0.2, \gamma_{g}=3.5, \gamma_{m}=4, \alpha=-1.75$, corresponding to the values for all species combined, expect for the slightly lower value of $\alpha$.

The sensitivity of optimal $c$ and RNI to the parameters $q, \gamma_{g}$ and $\gamma_{m}$ was estimated by varying these parameters through the range of parameter values observed in our data set (Tab. III). Baseline parameter values were taken from the results for all species pooled except for $\alpha$. For $\alpha$ a slightly higher value of -1.75 was chosen because this value is more in line with selfthinning studies that are based on much larger data sets than ours, e.g. (Weller, 1987). The results (Fig. 6) show that optimal $c$ is relatively insensitive to variation in all parameters except that it increases if $\gamma_{g}$ is significantly reduced. RNI on the other hand is sensitive to the relative size of self-thinned trees to the mean tree size $(q)$, whereas it is much less sensitive to $\gamma_{g}$ and $\gamma_{m}$.

\subsection{A thinning scenario application}

We illustrated the application of optimal closure in constructing a thinning scenario based on the thinning effects framework and the numerical results for optimal closure. 
To maximize current net increment in a thinning scenario, $c$ should be kept as near the optimum as possible. In theory this could be achieved by frequent thinnings that never allow the stand to deviate from the optimal $c$. In practice, thinnings are associated with costs and a very frequent thinning regime is not realistic. However, the peak of net increment as a function of $c$ is not particularly steep (Fig. 5), which means that some variation around the optimal density, for example between 0.5 and 0.9 , does not severely reduce net increment $(\approx 5 \%$ reduction compared to optimal $c$, for the pooled species parameter values; Fig. 5). At the same time, the frequency of thinnings can be significantly reduced compared to a narrower interval of allowed $c$ values.

Based on the above results, a thinning scenario is outlined as follows. After peak growth rate has been reached, the first thinning is performed according to a specified level $\left(f_{t}\right.$, fraction stem biomass removed). After the thinning the relative density of the stand $(c)$ will increase and eventually approach a closed stand (Fig. 3). The next thinning is triggered when the stand has reached a specified $c=c_{t}$. Thereafter, new thinnings are triggered each time $c$ reaches $c_{t}$. Thus, a thinning scenario is specified by the $B$ at initial thinning (at maximum growth rate), the fraction stem biomass removed $\left(f_{t}\right)$ and the value of $c$ that triggers a new thinning $\left(c_{t}\right)$. Figure 7 illustrates a thinning scenario compared to an un-thinned stand. In practice, it is however necessary to consider the development stage and the timing of final harvest before a thinning is done.

\section{DISCUSSION}

\subsection{General assumptions}

Our aim was to develop a model of thinning effects general enough to be applied to any even-aged forest stand and yet simple enough to be used without re-formulation for all forests in temperate or boreal regions. For this reason the model was based on the concept of closure (c), i.e. the stand density relative to maximum stand density and relative rates of growth and mortality, i.e. growth and mortality relative to a stand at maximum density $(c=1)$. Although a conceptually very similar approach has been presented before (Pretzsch, 2005), time based approaches are far more common. Commonly, effects of different densities after thinning are compared at the same points in time, which means that the responses will be strongly time dependent due to the closing of the stand over time and the differing growth rates at different densities. In contrast, our use of $c$, the density compared to maximum density at the same mean tree biomass (b), provides an invariable basis for evaluating density effects measured over different time spans. This model implies that site conditions affect only the rate of change but not the path of relative density and biomass development of a stand, which has ample empirical support (Long et al., 2004).

In using $c$ as the single control of density effects, independent of age or tree size, we implicitly assume that competition among trees and stand size structure qualitatively does not change significantly during stand development. Stability of size structure and competitive interactions in self-thinning
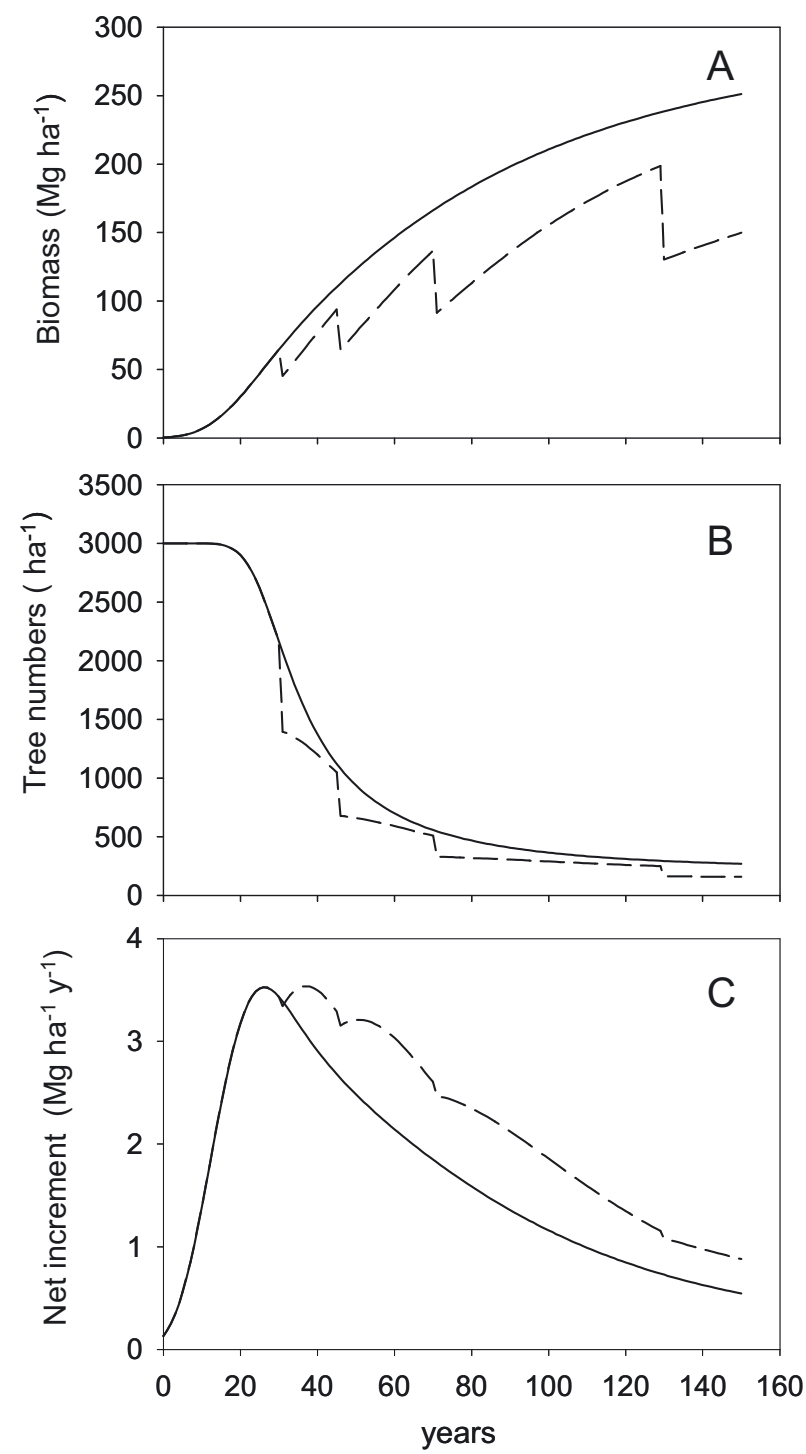

Figure 7. Examples of the development of un-thinned (solid line) and a thinned stand (dashed line) simulated with a forest growth model for un-thinned stands (Franklin et al., 2009) combined with the thinning scenario presented here, including the effect of competition un-related mortality (Eq. (7)). Thinnings that reduce closure $(c)$ to $c=0.6$ are triggered when $c>0.85$. The stand is Scots pine planted at 3000 trees per ha. Net increment (C) is gross biomass growth mortality.

stands of plants has been shown to result from asymmetric competition (larger trees affecting smaller trees much more than the other way around) (Hara, 1993). For older stands the role of competition may, however, change, leading to changes in size distributions (Coomes and Allen, 2007). Although this study does not include old-growth stands, equation (7) shows how the effect of reduced competition and relatively increased density independent mortality in older stands can be included in our model. A change in size distribution may also affect the relative size difference between self-thinned and surviving 
trees $(q)$, which would violate our assumption of constant $q$. For the two studies with more than one record of $q$ there was a clear increase over time for Scots pine (average $+64 \%$ over $10 \mathrm{y})$ but not for lodgepole pine $(+3.8 \%$ over $10 \mathrm{y})$. The increase in $q$ for Scots pine coincides with a reduction in increment of $32 \%$, which did not occur in the Lodgepole pine stand, and indicates that net growth rate of the Scots pine stand has passed its peak and is declining. Such aging of stands is associated with changes in size distribution and an increase in density independent mortality, as discussed above. Thus, density independent mortality of larger trees may explain the apparent increase in $q$ for Scots pine.

Because competition related mortality risk is strongly negatively correlated with individual tree growth rate within a stand (Wyckoff and Clark, 2002) one may expect that it is possible to make our mortality effect $\left(u_{m}\right)$ a function of the effect on growth $\left(u_{g}\right)$ and thereby simplify the model. However, we did not find any correlation between individual growth $\left(u_{g} / c\right)$ and mortality risk $\left(u_{m} / c\right)$ in response to stand closure among species. This result indicates that mortality risk is affected by other factors in addition to growth rate. For example, because mortality in contrast to growth is a threshold event for the individual, it could respond stronger to environmental variability than growth. Even if the mean resource availability and climate conditions over time are sufficient for survival, temporal fluctuations could cause mortality. Furthermore, it has been shown that while growth is closely linked to stand density, an additional density measure, gap fraction, affects mortality (Zeide, 2005). Clearly, our separate effects of density $(c)$ on mortality $\left(u_{m}\right)$ and growth $\left(u_{g}\right)$ cannot be uniquely combined to a common density effect, at least not without introducing a more complex density measure, which, however, would not be compatible with our aim of parsimony in order to facilitate wide applicability of the model.

It is implicit in our model that gross increment is maximized at $c=1$, which has been showed in previous studies of optimal density (Zeide, 2004). However, Zeide (2004) did not explicitly include mortality and did not find a simple relationship for optimal net increment due to interacting effects of stand density and $b$. In contrast, by our comparison of $c$ values at a common $b$ we avoid this interaction of effects and obtain an expression for optimal net increment as a trade-off between explicit mortality and growth effects.

\subsection{Optimal closure}

The estimated ranges of near optimum ( $>95 \%$ of maximum) $c$ in Figure 5 show that these ranges overlap for all species between $c=0.71$ to $c=0.81$, indicating that a $c$ around 0.75 may, in our framework, be generally applicable for optimal thinning (to maximize net increment) for most species. The range of near optimal $c$ for all species pooled $c=0.5$ to 0.9 is in general agreement with the results of thinning trials of (Assmann, 1961), reporting relative stand densities (basal area) between 0.6 and 0.9 as threshold for achieving optimum stem productivity. The sensitivity analysis indicated that optimal $c$ is quite robust with respect to variation in pa- rameter values although it is slightly increased with decreasing closure effect on growth $\left(\gamma_{g}\right)$, which acts to reduce the positive response of growth of remaining trees after a thinning (Fig. 6).

In comparison to optimal $c$, the maximum relative gain in net increment (RNI) is more variable among species, although the range of 4 to $16 \%$ is rather limited (Fig. 5). RNI is also more sensitive than optimal $c$ to parameter changes, particularly to the size ratio of self-thinning trees to the mean tree, $q$ (Fig. 6). The reason for the model sensitivity to $q$ is that this parameter determines the mortality rate (dead wood production) relative to net increment and thereby controls how much mortality can be avoided (and added to net increment) by thinning. Our data showed a variation in $q$ between 0.06 and 1.27, where the latter value (Monarch birch) was considered unrealistic and was therefore set to 1 . Such a high estimate of $q$ may indicate that the mortality was not due to competition and selfthinning and therefore not representative, as discussed above. If Monarch birch is excluded, our range of $q$ is between 0.06 and 0.321 . For additional assessment of $q$ variability, a simulation experiment was conducted with the hybrid patch model PICUS v1.4 (Seidl et al., 2005) that models mortality at the individual tree level. Starting from generic homogeneous initial stand conditions $100 \mathrm{y}$ simulations over an array of species and environmental conditions (cf. Seidl et al., 2009) resulted in values of $q$ between 0.5 and 0.25 .

Comparing species specific results, model results for Scots pine, both in terms of optimal $c(=0.9)$ and the low increase in net increment in thinned compared to closed stands $(\mathrm{RNI}=4 \%)$ is in agreement with results by Mäkinen and Isomäki (2004). For lodgepole pine our result for the gross and net increment as a function of $c$ are in reasonable agreement with the findings of Cochran and Dahms (2000). Our model study suggests that the potential increase in RNI may be higher for the deciduous broad-leafed species than for the needle leafed species (Fig. 5), which was previously observed when comparing beech $(\mathrm{RNI} \approx 20 \%)$ and spruce $(\mathrm{RNI} \approx 10 \%)$ (Pretzsch, 2005). Although there were significant differences in the closure effects on growth and mortality, $\gamma_{g}$ and $\gamma_{m}$, among species, these differences could be misleading because they could also be related to site differences. There are also differences in the self-thinning parameter $\alpha$ and the relative size of self-thinned trees $(q)$ among the species but more data is clearly needed to obtain confident conclusions about species or site effects. However, the requirement that data must include both increment and mortality in terms of both numbers and biomass (or volume) substantially limits the availability of suitable data.

An potential factor of uncertainty in the estimation of stemwood productivity gain of thinning is related to the potential delay in growth response after a thinning due to a phase of physiological acclimation as discussed above (Materials and methods -thinning effects). Such an effect would reduce the potential gain of a thinning but would not affect the optimal $c$. The delay could significantly affect the optimal frequency of thinnings if the phase of acclimation covers a significant proportion of the growing time, which, however, was not found in the experiments analyzed in our study. 


\subsection{Limitations and potential extensions}

An approach based on self-thinning as a function of mean tree size does not adequately represent strongly age- heterogeneous stands and is not applicable to management systems such as continuous cover forestry or variable retention systems, which are increasingly discussed as alternatives to evenaged management strategies (cf. Seidl et al., 2008).

Due to limited data availability, our model does not include effects of site conditions on the thinning response. This is a clear limitation of the model as several studies point at considerably varying responses with local site conditions (e.g., Pretzsch, 2005). Underlying these empirical observations are, however, complex interactions of environmental and physiological factors, such as soil fertility, soil depth, water availability, climate and disturbance. These interactions are rarely represented at the data resolution available at continental scales and they are quantitatively not well understood in terms of general relationships valid across species and environmental conditions, which prevent their inclusion in our model. Interactions among resource availability, climate and density relationships remain an interesting topic for further research and potential development of more detailed models.

Considering that a main aspect of thinning, besides focusing growth on the remaining individuals, is to improve stand stability and quality, neglecting these aspects in taking a mean tree approach might represent another limitation of the presented model. While generic effects on the stand collective can be mimicked by means of the relative size of removed trees (e.g., thinning from above, thinning from below - see Fig. 1) the approach lacks the flexibility of individual-tree models with regard to spatially heterogeneous and selective approaches (cf. Hasenauer, 2006) Furthermore, although we consider thinning-related biomass (or volumetric) changes of the mean tree in our model, allocational shifts in stem allometry between e.g., height and diameter increment are not explicitly included. A simple way to obtain the effects on diameter growth would be to assume that mean tree height is not affected by thinning (e.g. Cochran and Dahms, 2000) and use allometric functions to derive the effects on diameter directly from biomass results.

Overall, considering that model complexity is strongly determined by the intended domain of application we believe that the presented approach is a reasonable compromise between ecological realism and general, large-scale applicability.

\subsection{Conclusions for model applicability}

For prognostic modeling our use of relative, site- and productivity-independent changes in gross growth $\left(u_{g}\right)$ and mortality $\left(u_{m}\right)$ allows integration with any existing forest increment model for un-thinned stands. In combination with equations for tree numbers (Eq. (8)) and closure (Eq. (9)), stand development in terms of biomass, dead wood and associated tree numbers can be obtained for an arbitrary thinning scenario. The simplicity of the approach makes it potentially useful for large scale, continental and global modeling of net increment and mortality where site information is limited or non-existing, or where computation time (e.g. in dynamic optimization frameworks) or ease of mathematical integration is an issue. For example, the approach could add realism to large scale policy related analyses (e.g. Böttcher et al., 2008) or for analyses using global dynamic vegetation models (e.g. Zaehle et al., 2006).

The presented framework is an attempt to transfer the detailed accumulated knowledge on thinning responses represented in detailed growth and yield models (e.g., overviews in Hasenauer, 2006; Söderbergh and Ledermann, 2003) and thinning experiments to model frameworks at larger spatial scales in a general and physiologically meaningful set of equations. This approach necessarily sacrifices complexity and details compared to comprehensive individual-based models (Crookston and Dixon, 2005; Hyytiäinen et al., 2004; Sterba and Monserud, 1997). However, the selected mean tree approach is a structural advancement of the state of the art compared to structurally simple scenario tools applied at continental scale (e.g. Schelhaas et al., 2007). In conclusion, introducing a generic thinning framework as presented in this study in large scale scenario analyses of forest resource development could significantly increase their realism with regard to the silvicultural decision space in forest management.

Acknowledgements: We thank Hannes Böttcher at IIASA for helpful comments on the manuscript. We are furthermore grateful to two anonymous reviewers for helping to improve an earlier version of the manuscript. This research received funding from the European Community's 7th Framework Programme (FP7) under the grant 212535, Climate Change - Terrestrial Adaptation and Mitigation in Europe (CC-TAME), www.cctame.eu, and from the 6th Framework Programme (FP6) under the grant SSPI551 CT-2003/503614 (INSEA).

\section{REFERENCES}

Asai T., 1997. Effect of varying thinning densities on tree growth in a Japanese birch forest. Hokkaido Branch Journal of Japanese Forest Research 45: 50-52.

Assmann F., 1961. Waldertragskunde. Organische Produktion, Struktur, Zuwachs und Ertrag von Waldbeständen. BLV Verlagsgesellschaft, München, $490 \mathrm{p}$.

Böttcher H., Freibauer A., Obersteiner M., and Schulze E.D., 2008. Uncertainty analysis of climate change mitigation options in the forestry sector using a generic carbon budget model. Ecol. Model. 213: 45-62

Cochran P.H. and Dahms W.G., 2000. Growth of lodgepole pine thinned to various densities on two sites with differing productivities in central Oregon. USDA Forest Service, Research Papers RMRS, pp. $1-59$.

Coomes D.A. and Allen R.B., 2007. Mortality and tree-size distributions in natural mixed-age forests. J. Ecol. 95: 27-40.

Crookston N.L. and Dixon G.E., 2005. The forest vegetation simulator: A review of its structure, content, and applications. Comput. Electron. Agric. 49: 60-80.

Dewar R.C. and Porte A., 2008. Statistical mechanics unifies different ecological patterns. J. Theor. Biol. 251: 389-403.

Franklin O., Moltchanova E., Obersteiner M., Kraxner F., Seidl R., Böttcher H., and Rokityianskiy D., 2009. A European scale forest growth and thinning model-deducing productivity and stand density from inventory data manuscript. 
Garcia O., 1990. Growth of Thinned and Pruned Stands. In New approaches to spacing and thinning in plantation forestry. Proceedings of a IUFRO symposium, Rotorua, New Zealand, April 1989, James R.N., Tarlton G.L. (Eds.)., New Zealand Ministry of Forestry, Forest Research Institute.

Hara T., 1993. Model of competition and size-structure dynamics in plant communities. Plant Species Biol. 8: 75-84.

Hasenauer H., 2006. Concepts within tree growth modeling. In: Hasenauer H. (Ed.), Sustainable Forest Management. Growth Models for Europe, Berlin, pp. 3-17.

Hynynen J., Ahtikoski A., Siitonen J., Sievänen R., and Liski J., 2005. Applying the MOTTI simulator to analyse the effects of alternative management schedules on timber and non-timber production. For. Ecol. Manage. 207: 5-18.

Hyytiäinen K., Hari P., Kokkila T., Maäkela A., Tahvonen O., and Taipale J., 2004. Connecting a process-based forest growth model to standlevel economic optimization. Can. J. For. Res. 34: 2060-2073.

Johnstone W.D., 2002. Thinning Lodgepole Pine in Southeastern British Columbia: 46-year Results. Res. Br., B.C. Min. For., Victoria, B.C., Work. Pap. 63.

Keane R.E., Austin M., Field C., Huth A., Lexer M.J., Peters D., Solomon A., et al., 2001. Tree mortality in gap models: Application to climate change. Clim. Change 51: 509-540.

Kurz W.A. and Apps M.J., 1999. A 70-year retrospective analysis of carbon fluxes in the Canadian Forest Sector. Ecol. Appl. 9: 526-547.

Long J.N., Dean T.J., and Roberts S.D., 2004. Linkages between silviculture and ecology: Examination of several important conceptual models. For. Ecol. Manage. 200: 249-261.

Mäkinen H. and Isomäki A., 2004. Thinning intensity and growth of Scots pine stands in Finland. For. Ecol. Manage. 201: 311-325.

Mason E.G. and Dzierzon H., 2006. Applications of modeling to vegetation management. Can. J. For. Res. 36: 2505-2514.

Medhurst J.L. and Beadle C.L., 2005. Photosynthetic capacity and foliar nitrogen distribution in Eucalyptus nitens is altered by high-intensity thinning. Tree Physiol. 25: 981-991.

Monserud R.A. and Sterba H., 1999. Modeling individual tree mortality for Austrian forest species. For. Ecol. Manage. 113: 109-123.

Montero G., Canellas I., Ortega C., and Del Rio M., 2001. Results from a thinning experiment in a Scots pine (Pinus sylvestris L.) natural regeneration stand in the Sistema Iberico Mountain Range (Spain). For. Ecol. Manage. 145: 151-161.

Newnham R.M., 1964. The development of a stand model for Douglas fir. Ph.D. thesis, University of British Columbia, Vancouver, 201 p.

Norgrove L. and Hauser S., 2002. Measured growth and tree biomass estimates of Terminalia ivorensis in the 3 years after thinning to different stand densities in an agrisilvicultural system in southern Cameroon. For. Ecol. Manage. 166: 261-270.

Omule S.A.Y., 1988. Growth and yield 35 years after commercially thinning 50-year-old Douglas-fir. Can. For. Serv. and B.C. Min. For., Victoria, B.C., FRDA Rep. 021: 7.

Petritsch R., Hasenauer H., and Pietsch S.A., 2007. Incorporating forest growth response to thinning within biome-BGC. For. Ecol. Manage. 242: $324-336$.
Pretzsch H., 2005. Stand density and growth of Norway spruce (Picea abies (L.) Karst.) and European beech (Fagus sylvatica L.): Evidence from long-term experimental plots. Eur. J. For. Res. 124: 193-205.

Pukkala T., Miina J., and Palahi M., 2002. Thinning response and thinning bias in a young Scots pine stand. Silva Fenn. 36: 827-840.

Reineke L.H., 1933. Perfecting a stand-density index for even-aged forests. J. Agric. Res. 46: 627-638.

Schelhaas M.J., Eggers J., Lindner M., Nabuurs G.J., Pussinen A., Päivinen R., Schuck A., et al., 2007. Model documentation for the European Forest Information Scenario model (EFISCEN 3.1.3), EFI Technical Report.

Seidl R., Lexer M.J., Jäger D., and Hönninger K., 2005. Evaluating the accuracy and generality of a hybrid patch model. Tree Physiol. 25: 939-951.

Seidl R., Rammer W., Lasch P., Badeck F.W., and Lexer M.J., 2008. Does conversion of even-aged, secondary coniferous forests affect carbon sequestration? A simulation study under changing environmental conditions. Silva Fenn. 42: 369-386.

Seidl R., Rammer W., and Lexer M., 2009. Schätzung von Bodenmerkmalen und Modellparametern für die Waldökosystemsimulation auf Basis einer Großrauminventur. Allg. Forst-Jagdztg 180: $35-44$.

Siitonen M., Härkönen K., Kilpeläinen H., and Salminen O., 1999. MELA Handbook - 1999 edition. The Finnish Forest Research Institute. 492 p.

Söderbergh I. and Ledermann T., 2003. Algorithms for simulating thinning and harvesting in five european individual-tree growth simulators: A review. Comput. Electron. Agric. 39: 115-140.

Sterba H. and Monserud R.A., 1997. Applicability of the forest stand growth simulator PROGNAUS for the Austrian part of the Bohemian Massif. Ecol. Model. 98: 23-34.

Tang S., Meng Chao H., Meng Fan R., and Wang Young H., 1994. A growth and self-thinning model for pure even-age stands: Theory and applications. For. Ecol. Manage. 70: 67-73.

Watanabe I., 2002. Thinning effect and crown dieback in a mature secondary stand of Betula maximowicziana established after fire. Bulletin of Hokkaido Forestry Research Institute, 39 p.

Weller D.E., 1987. A re-evaluation of the $-3 / 2$ power rule of plant selfthinning. Ecol. Monogr. 57: 23-43.

Wyckoff P.H. and Clark J.S., 2002. The relationship between growth and mortality for seven co-occurring tree species in the southern Appalachian Mountains. J. Ecol. 90: 604-615.

Zaehle S., Sitch S., Prentice I.C., Liski J., Cramer W., Erhard M., Hickler T., et al., 2006. The importance of age-related decline in forest NPP for modeling regional carbon balances. Ecol. Appl. 16: 1555-1574.

Zeide B., 2001. Natural thinning and environmental change: An ecological process model. For. Ecol. Manage. 154: 165-177.

Zeide B., 2004. Optimal stand density: A solution. Can. J. For. Res. 34: 846-854.

Zeide B., 2005. How to measure stand density. Trees 19: 1-14. 